\title{
BMJ Open Conceptualising centres of excellence: a scoping review of global evidence
}

\author{
Tsegahun Manyazewal (i) , ${ }^{1}$ Yimtubezinash Woldeamanuel, ${ }^{1}$ Claire Oppenheim, ${ }^{2}$ \\ Asrat Hailu, ${ }^{1}$ Mirutse Giday, ${ }^{1,3}$ Girmay Medhin, ${ }^{1,3}$ Anteneh Belete, ${ }^{1}$ Getnet Yimer, ${ }^{1,4}$ \\ Asha Collins, ${ }^{1}$ Eyasu Makonnen, ${ }^{1}$ Abebaw Fekadu (1) ${ }^{1,5}$
}

To cite: Manyazewal T, Woldeamanuel Y, Oppenheim C, et al. Conceptualising centres of excellence: a scoping review of global evidence. BMJ Open 2022;12:e050419. doi:10.1136/ bmjopen-2021-050419

- Prepublication history and additional supplemental material for this paper are available online. To view these files, please visit the journal online (http://dx.doi.org/10.1136/ bmjopen-2021-050419).

Received 20 February 2021 Accepted 11 January 2022

Check for updates

(c) Author(s) (or their employer(s)) 2022. Re-use permitted under CC BY-NC. No commercial re-use. See rights and permissions. Published by BMJ.

${ }^{1}$ Center for Innovative Drug Development and Therapeutic Trials for Africa (CDT-Africa), College of Health Sciences, Addis Ababa University, Addis Ababa, Ethiopia

${ }^{2}$ Department of Psychiatry, Boston University School of Medicine, Boston,

Massachusetts, USA

${ }^{3}$ Aklilu Lemma Institute of Pathobiology, Addis Ababa University, Addis Ababa, Ethiopia ${ }^{4} \mathrm{Global}$ One Health Eastern Africa Office, Office of International Affairs, The Ohio State University, Columbus, Ohio, USA

${ }^{5}$ Global Health and Infection Department, Brighton and Sussex Medical School, Brighton, UK

Correspondence to Dr Tsegahun Manyazewal; tsegahunm@gmail.com

\section{ABSTRACT}

Objective Globally, interest in excellence has grown exponentially, with public and private institutions shifting their attention from meeting targets to achieving excellence. Centres of Excellence ( $\mathrm{CoEs}$ ) are standing at the forefront of healthcare, research and innovations responding to the world's most complex problems. However, their potential is hindered by conceptual ambiguity. We conducted a global synthesis of the evidence to conceptualise CoEs.

Design Scoping review, following Arksey and O'Malley's framework and methodological enhancement by Levac et $\mathrm{al}$ and the Preferred Reporting Items for Systematic Reviews and Meta-Analyses extension for Scoping Reviews.

Data sources PubMed, Scopus, CINAHL, Google Scholar and the Google engine until 1 January 2021.

Eligibility Articles that describe $\mathrm{CoE}$ as the main theme.

Results The search resulted in 52161 potential publications, with 78 articles met the eligibility criteria. The 78 articles were from 33 countries, of which 35 were from the USA, 3 each from Nigeria, South Africa, Spain and India, and 2 each from Ethiopia, Canada, Russia, Colombia, Sweden, Greece and Peru. The rest 17 were from various countries. The articles involved six thematic areas-healthcare, education, research, industry, information technology and general concepts on $\mathrm{CoE}$. The analysis documented success stories of using the brand 'CoE' - an influential brand to stimulate best practices. We identified 12 essential foundations of $\mathrm{CoE}$ - specialised expertise; infrastructure; innovation; high-impact research; quality service; accreditation or standards; leadership; organisational structure; strategy; collaboration and partnership; sustainable funding or financial mechanisms; and entrepreneurship.

Conclusions CoEs have significant scientific, political, economic and social impacts. However, there are inconsistent use and self-designation of the brand without approval by an independent, external process of evaluation and with high ambiguity between 'CoEs' and the ordinary 'institutions' or 'centres'. A comprehensive framework is needed to guide and inspire an institution as a $\mathrm{CoE}$ and to help government and funding institutions shape and oversee CoEs.

\section{INTRODUCTION}

Globally, interest in excellence has grown exponentially, with public and private

\section{Strengths and limitations of this study}

To the best of our knowledge, this is the first scoping review to conceptualise centres of excellence based on global evidence.

- The study followed Arksey and 0'Malley's framework and methodological enhancement by Levac et al to analyse the evidence and the Preferred Reporting Items for Systematic Reviews and Meta-Analyses extension for Scoping Reviews methodological frameworks to guide the retrieval and inclusion of the evidence.

- Five databases were systematically searched to identify scientific and grey literature.

The study was limited by language restrictions.

institutions shifting their attention from meeting targets to achieving excellence. ${ }^{12}$ The term centre of excellence ( $\mathrm{CoE}$ ) has been understood as a team, shared facility or entity that provides high standards of research, leadership, services or education, and brings innovative mechanisms to promote knowledge and scientific advancements. ${ }^{1-3}$ The concept has been around since copyrighted by Humana Health $\mathrm{Plan}^{4}$; drawing the attention of scientists to enhance collaborations and cultivate access to resources essential for advanced research. ${ }^{5}$ It has been shaping institutions with ways to consolidate and build on their expertise and develop the capacity for scientific and financial gains. ${ }^{6}$ Organisations that work under the CoE model have been pooling existing highly skilled expertise and resources to work hard on their focus area and bring in superior performance and productivity over the others. ${ }^{7}$ The organisations leverage $\mathrm{CoE}$ as a specific mechanism to establish and drive world-class excellence within their technical or functional space.

Nonetheless, there has been no consensus as to what $\mathrm{CoE}$ means and what operational modalities it should follow and be ruled by. ${ }^{68}$ Although many centres are determined as CoE, there is no sufficient clarity as to what 
constitutes a CoE, the resource requirements, the nature of change they would make, and the processes and activities necessary to sustain the CoE. In the area of healthcare, $\mathrm{CoE}$ has been looked at as a specialised programme with potential expertise and resources focusing on particular medical areas and providing exceptional outcomes. ${ }^{9} 10$ Some experts in the field pinpoint particular fronts that distinguish $\mathrm{CoE}$ from traditional healthcare delivery models-organisation design, servicescape design, personnel, medical care, marketing and finance. ${ }^{9} 11$ Moreover, many research and higher education institutions ${ }^{12-16}$ and healthcare institutions ${ }^{17-20}$ across different countries have pursued a CoE status with claims that such institutions have bold distinctions in capacity, resources and outcomes even among themselves. For instance, the African Research Universities Alliance (ARUA) establishes CoEs within its member universities where worldclass researchers from member universities assemble to carry out joint researches in 13 priority thematic areas. Drawing on existing university infrastructure and human resources, each CoE needs to bring together leading researchers from Africa and elsewhere in working groups and conduct cutting-edge research that is innovative and with the potential for transformation. ARUA explains $\mathrm{CoE}$ as an assembly point for good and committed researchers and students seeking to do cutting-edge work. It conceptualises CoE as a team, a shared facility, or an entity that provides leadership, best practices, research, support and/or training for a focus area which might be a technology, a business concept, a skill or a broad area of study.

Despite these assertions, there is ambiguity and inconsistency in the use of the term, the process of designations, processes of evaluation, and metrics. In this study, we conducted a global synthesis of the evidence to conceptualise CoEs.

\section{METHODS}

We followed a scoping review procedure to provide greater conceptual clarity and map CoE from heterogeneous sources. Scoping review is the most preferred approach to systematically identify and map key concepts, theories and sources of emerging evidence and gaps in the research. We used Arksey and O'Malley's framework for scoping reviews, ${ }^{21}$ which has been further enhanced by Levac et $a l,{ }^{22}$ to analyse the evidence. We also used the Preferred Reporting Items for Systematic Reviews and Meta-Analyses extension (PRISMA) for Scoping Reviews ${ }^{23}$ to guide the retrieval and inclusion of the evidence. The review was conducted following the stages described below:

\section{Stage 1: identifying the research question}

This stage involved in-depth discussion and consultation with the study team and study collaborators. The main research questions were the following:

- How are CoEs defined?

- What are the building blocks of a CoE?
What are the frameworks and functions of CoEs?

What does it need to establish and sustain a CoE?

\section{Stage 2: identifying relevant studies \\ Search strategy and sources}

Relevant empirical and peer-reviewed literature were sourced from electronic databases and search engines including PubMed, Scopus, CINAHL and Google Scholar up to 1 January 2021. Handsearching of contents was conducted for key journals including the Journal of Excellence, International Journal of Excellence in Education, Journal on Centers for Teaching and Learning, International Journal of Business Excellence, Journal of Excellence in College Teaching, Equity and Excellence in Education, Excellence in Medical Education, Journal of Universal Excellence, Excellence International Journal of Education and Research, and Measuring Business Excellence. A precise search strategy for one database is included in online supplemental table 1.

To ensure that all relevant information were captured, we searched the Google engine for grey literature including conference proceedings, working papers, newsletters, business documents, presentations and reports, government documents, technical documents, white papers, policies and bulletins. The references of included literature and documents were also handsearched to get any additional evidence.

The databases were searched using both natural language and controlled vocabulary for 'excellence' and the following terms within publication title and/ or abstract: Centers of Excellence; Centers of Excellence for Education; Centers of Excellence for Research; Sustaining Centres of Excellence; Barriers to Achieving Excellence; Leadership for Excellence; Promoters of Excellence; Infrastructure for Excellence; and Collaborations for Excellence. The search term "Excellence" was further extended to include all relevant words through a search of definitions from dictionaries.

\section{Eligibility}

To be included in the review, sources of evidence needed to describe $\mathrm{CoE}$ as the main theme, which could be defining, theorising, implementing or evaluating a CoE. The search had no restrictions applied on the year of publication, publication status or geographical location to ensure comprehensiveness of coverage, while nonEnglish language literature were excluded. Duplicate citations were also excluded from the initial database.

\section{Stage 3: study selection}

An extensive title screening, summary screening, and fulltext screening strategy were developed to identify all relevant literature and documents. The title and abstract of all records retrieved were downloaded to and independently assessed for eligibility and screened by two authors after removal of duplicates. Disagreements between the reviewers were decided by consensus. Full-text copies of 
potentially relevant papers were retrieved for in-depth review.

\section{Stage 4: data charting}

Data extraction used a standardised form developed by the investigator team. Information was extracted from each included document on (1) description of the document, including the primary author, publication year and search engine; (2) Thematic area; (3) Essential foundations of the $\mathrm{CoE}$ and (4) description of the major finding of the article. We checked if the CoEs had their status approved by an independent body or if they have a standard recognition to function as a CoE. We also checked if the CoEs have described the major barriers and opportunities in the establishment and sustaining of their CoE. Before extracting the actual data, the data extraction sheet was pilot-tested on 10 randomly selected studies, and the extraction sheet was refined as needed. Two authors (TM and AF) extracted the data.

\section{Stage 5: collating, summarising and reporting the results}

The results of the review were synthesised and narratively reported. The steps included thematic content analysis for qualitative information; numerical counts and tables for quantitative data; narrative summary and interpretation of all the results; and discussion of gaps in the literature.

Assessing the risk of bias across studies was not feasible due to expected high levels of variation in scope, setting, and time between studies. All given results were included to minimise the risk of selective reporting.

\section{Patient and public involvement}

No patient was involved.

\section{RESULTS}

\section{Study selection in the PRISMA review}

Overall, 52161 potential documents were included in the initial review from PubMed ( $\mathrm{n}=15778)$, Scopus $(\mathrm{n}=7168)$, CINAHL ( $\mathrm{n}=1150)$, Google Scholar ( $\mathrm{n}=10$ 213), Google engine $(n=8142)$ and other sources $(n=23)$, of which 23432 were retained after removing duplicates. Following an initial screening, 346 full-text articles were evaluated, of which 78 met the inclusion criteria and were included in the review (figure 1).

\section{Characteristics of the included studies}

The 78 full-text articles included were affiliated with institutions globally from 33 countries, of which 35 were from the USA, 3 each from Nigeria, South Africa, Spain, and India, and 2 each from Ethiopia, Canada, Russia, Colombia, Sweden, Greece and Peru. The rest 17 were from various countries.

The articles involved six thematic areas-health services, education, research, industry, information technology and a general concept of CoE. See online supplemental table 2 for detailed information on individual study characteristics, including the name of the primary author and publication date, country of study

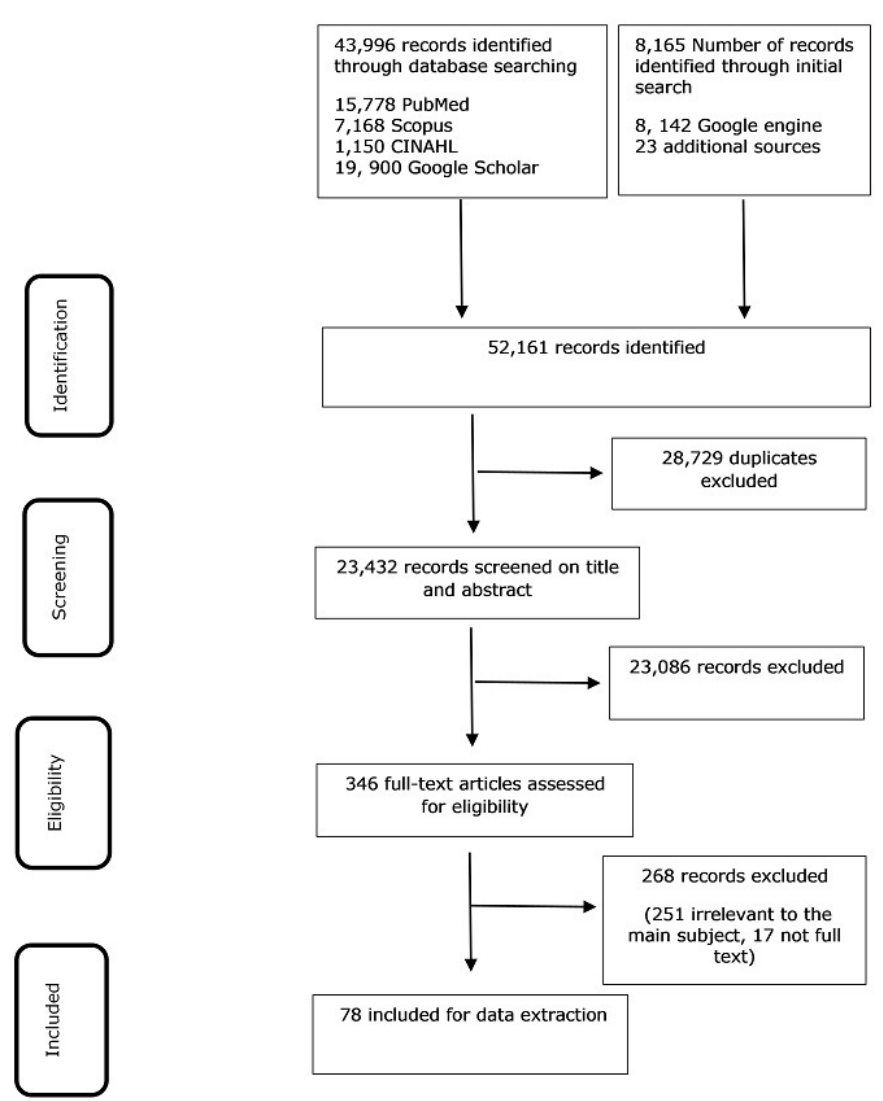

Figure 1 Flow diagram of the study.

origin, name of the designated CoE if any, thematic area of the literature, the essential foundation of the $\mathrm{CoE}$ and a brief description of the key message in the literature.

\section{Definition of CoE}

$\mathrm{CoE}$ is a team of specialised expertise ${ }^{271724-47}$ or organisational environment ${ }^{252430353648-56}$ that is established to provide outstanding healthcare, 271217 24-39 41485051 57-74 research, ${ }^{12} 1724$ 26-28 $31364041505258687274-85$ education and training, ${ }^{12} 17242531363842436873747681-8385-88$ regulatory, ${ }^{578389}$ policy, 46454558290 information technology ${ }^{45391}$ or industrial $^{449293}$ services and support in high levels of efficient and effective performance. CoEs are geographically concentrated and focused on high potential in science and industry, ${ }^{46}$ as a world leader or a catalyst between neighbouring countries, ${ }^{60} 7282$ anywhere from the local research and development (R\&D) group up to a network of cooperative partners. They are characterised by the scope of their operations, mandates, funding, executive sponsorship, commitment, responsibilities and powers. ${ }^{94}$ Historically, CoE is leveraged by IT leaders seeking to facilitate the creation of hubs for knowledge sharing and building and enhancing capabilities. The idea had evolved and been used in favour of different targets in the last decade. ${ }^{55}$ Its driver, 'Excellence', was not considered an act that has to do with the end product, but a habit to do with the process. 


\section{Functions of $\mathrm{CoE}$}

When a CoEs is established, it is most often because of a need for implementation infrastructure, the existence of specific relationships, and availability of funding. ${ }^{49}$ Its establishment could favour critical research infrastructure, foster collaboration, train experts and share core facilities ${ }^{68}$ Regardless of strategic orientation, all CoEs have in common the notion of excellence and the particular requirements that come with that label, such as high research quality and productivity, resource attraction and concentration, international visibility and attractiveness, and organisational robustness. ${ }^{46}$

Within the vertically different higher education, excellence is being equated to 'being better' which could mean, excellence in research, top-quality professors, favourable working conditions, job security and good salary and benefits, adequate facilities, adequate funding, academic freedom, an atmosphere of intellectual excitement and faculty self-governance. ${ }^{95}$ Higher education institutions develop such CoEs to address the ongoing critical need for more intensive and specialised training on a specific condition. ${ }^{128195}$

In the healthcare sector, CoEs can provide breakthrough treatments on specific disease conditions. ${ }^{26-33} \mathrm{In}$ line with the current COVID-19 pandemic, some hospitals and universities have established COVID-19-specific CoEs. ${ }^{24} 96$

CoE could be established to provide specific regulatory decision making, including to advance the development and regulation of products ${ }^{25} 83$ and to fill in knowledge gaps. ${ }^{97}$ For instance, the World Bank has an Eastern and Southern Africa Higher Education Centers of Excellence project that strengthen selected Eastern and Southern African higher education institutions to deliver quality postgraduate education and build collaborative research capacity in the regional priority areas. ${ }^{82}$

\section{Essential foundations of $\mathrm{CoE}$}

There were 12 essential foundations on which $\mathrm{CoE}$ could be based according to the review of the 78 literature (figure 2). Gaining and retaining such foundations could cultivate the good nature of a $\mathrm{CoE}$, creating more realistic possibilities and opportunities to function as a CoE.

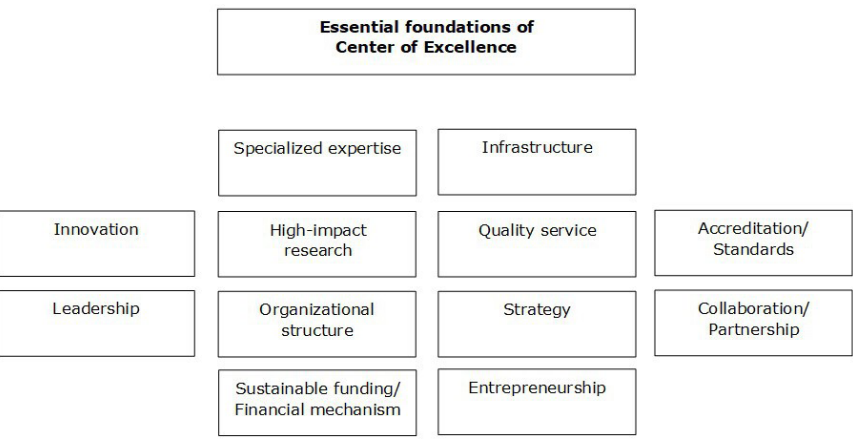

Figure 2 Essential foundations of $\mathrm{CoE}$ in literature. CoE, centres of excellence.
Table 1 Frameworks and models of centres of excellence (CoE)

\begin{tabular}{|c|c|}
\hline Framework or model & $\begin{array}{l}\text { Literature that cited the } \\
\text { framework/model }\end{array}$ \\
\hline $\begin{array}{l}\text { Willis-Knighton's Health System CoE } \\
\text { delivery model }\end{array}$ & Elrod et $\left.a\right|^{2}$ \\
\hline $\begin{array}{l}\text { REAL-PANLAR Group quality standard } \\
\text { requirements for CoE model }\end{array}$ & Santos-Moreno et al $l^{7}$ \\
\hline Activity-based typing of CoEs & Heyes $^{47}$ \\
\hline Critical capacities of a CoE & Mettrick et al ${ }^{49}$ \\
\hline $\begin{array}{l}\text { Generalised Criteria and Evaluation Method } \\
\text { for CoE }\end{array}$ & Craig et $a l^{53}$ \\
\hline Key steps to establishing a CoE & Patel et $a l^{54}$ \\
\hline $\begin{array}{l}\text { IFSO requirement for CoE programme } \\
\text { participation }\end{array}$ & Melissas et al ${ }^{60}$ \\
\hline Lean Six Sigma & Itri et $a l^{64} ;$ Ferguson et $a /^{66}$ \\
\hline E-CoRE conceptual framework & Househ et $\mathrm{al}^{72}$ \\
\hline Three-impact dimensions & Borlaug $^{79}$ \\
\hline Research Excellence Framework & Terama et $\mathrm{al}^{84}$ \\
\hline Curriculum development framework & Cofrancesco ${ }^{85}$ \\
\hline Four-domain curricular model & Rugen et $a l^{86}$ \\
\hline $\begin{array}{l}\text { Excellence in higher education evaluation } \\
\text { model }\end{array}$ & Brusoni et a $\left.\right|^{94}$ \\
\hline
\end{tabular}

\section{Frameworks and models of CoE}

Fourteen of the 78 included articles have used or developed a specific framework or model to establish and shape their institutions as a $\mathrm{CoE}$ or to distinguish $\mathrm{CoE}$ from the traditional institutional or service delivery model. Table 1 summarises the frameworks employed.

Elrod and Fortenberry ${ }^{2}$ looked at CoE under the umbrella of the Willis-Knighton Health System and identified six particular fronts-organisation design, servicescape design, personnel, medical care, marketing and finance-that distinguish CoE from traditional healthcare delivery models. Addressing each of these fronts yield an exceptionally high level of care largely exceeding that delivered in traditional settings. Elrod and Fortenberry considered $\mathrm{CoE}$ in healthcare as a programme that is assembled to supply an exceptionally high concentration of expertise and related resources centred on a particular area of medicine, delivering associated care in a comprehensive, interdisciplinary fashion to afford the best patient outcomes possible.

Santos-Moreno et $a l^{7}$ employed the REAL-PANLAR Group model as a requirement for implementation and accreditation of CoEs in rheumatoid arthritis care. The framework defined three types of CoEs based on structure, process, and outcome indicators-standard, optimal and model. To maintain the comprehensive nature of care, all criteria must be met with a minimum score of $80 \%$ for each of the criteria. The approved standards for the 'standard' CoE should have a basic structure and process indicators, the 'optimal' level should accomplish more structure and process indicators, and the 'model' level should fulfil outcome and patient experience indicators. 
In addition and regardless of institutional category, all CoEs should meet the same standards, and according to the philosophy of the accreditation system, the concepts of continuous improvement and patient-centred management must be included.

Heyes ${ }^{47}$ as part of his assessment of the nuclear security CoEs, grouped CoEs into five types based on their core activities. Group A centres where the core activities are essentially technical and scientific with a focus on providing training on the use, calibration, and maintenance of equipment. Group B centres where the core activities are essentially educational, offering the course(s) which, although they may have technical content, are designed to provide a broad perspective of nuclear security and an awareness of relevant issues. Group C centres where the core activities encompass a wider range of topics than just nuclear security, or even wider than nuclear security, safety, and safeguards. Group D centres where the core activity is focused on nuclear R\&D or which are characterised by strong commercially driven objectives. Group E centres where the core activities are focused on raising awareness of nuclear security issues within the nuclear industry and beyond.

Mettrick $e t a t^{49}$ indicated that every CoE's scope of work should have four critical capacities - implementation support, continuous quality improvement for identified interventions, workforce development and technical assistance. As the initial scope of work is refined, these criteria should be used to begin to identify possible organisational candidates to house the CoE.

Craig et $a \tilde{l}^{3}$ proposed a framework that characterised the successes of a CoE through five dimensions-internal business process, customer focus, leadership, innovation and learning, and finance. The framework integrated elements of the balanced scorecard and the Baldrige Criteria for Performance Excellence to form a background for evaluating organisations as CoE.

Patel and Andrews ${ }^{54}$ proposed a seven key-steps framework to consider in creating a CoE. The steps included defining the CoE and setting vision statement and guiding principles, determining the overall scope for the COE which has three types including knowledge-sharing focus, strategy/guidance focus and strategy/guidance focus with implementation/support focus.

Melissas et $a l^{60}$ applied the IFSO (International Federation for the Surgery of Obesity and Metabolic Disorders) requirement for $\mathrm{CoE}$ programme participation. The IFSO provides designation as CoE in bariatric and metabolic surgery for institutions fulfilling ten requirements focusing on experts' capacity, infrastructure, a facility set up and appropriate technologies. The authors improved healthcare services following participation in the IFSO.

Itri $e t a l^{64}$ and Ferguson et $a l^{66}$ used the Lean Six Sigma framework with its five distinct phases-define, measure, analyse, improve and control- to establish CoE in healthcare settings. The authors proved that the framework is effective in establishing and organising CoEs.
Househ $e t a l^{72}$ were guided by a conceptual framework that is comprised of the production, dissemination, and use of knowledge in their establishment of an Electronic Health Centre of Research Excellence. In the framework, knowledge was produced as a result of research efforts, innovation and collaboration, and such generated information is used to formulate decisions.

Borlauge ${ }^{79}$ developed a conceptual framework involving three impact dimensions-organisational, social and international-to examine how CoE schemes have been adapted to two distinct national public research systems in Norway and Sweden. With this framework, the author identified that funding agencies emphasised organisational impact in a country with a highly competitive funding system.

Terama et $a l^{84}$ applied Research Excellence Framework to assess the quality and reach of research in UK universities and allocate funding accordingly. The framework assesses the quality of research in higher education institutions in terms of three elements-originality, significance and rigour of research outputs; reach and significance of impact; and vitality and sustainability of research environment. The framework was instrumental in establishing education excellence, while it was unlikely to fully reflect all of the impacts of university research.

Cofrancesco $e t a l^{85}$ used the six-step curriculum development framework to inspire and support the development and outcomes of excellence in education programmes. The steps included problem identification and general needs assessment; targeted needs assessment; setting goals and objectives; educational strategies; programme implementation; and evaluation and feedback. The authors developed and implemented the Institute for Excellence in education as a structure that works to promote, improve and innovate medical and biomedical education and scholarship.

Rugen $e t a l^{86}$ developed a curricular model with four domains-shared decision making, sustained relationships, interprofessional collaboration and performance improvementCofrancescoaimed at achieving $\mathrm{CoE}$ in primary care education. The model transformed healthcare training from a profession-specific primary care delivery approach to an inter-professional, team-based, patient-centred care delivery paradigm.

Brusoni $e t a l^{4}$ framed seven evaluation extents to define excellence in higher education-leadership, purposes and plans, beneficiaries and constituencies, programmes and services, faculty/staff and workplace, assessment and information use, and outcomes and achievements. Excellence in Higher Education provides a structured guide for reviewing each of these areas as they operate within a particular institution, department or programme.

\section{DISCUSSION}

Our analysis of the scientific and grey literature documented success stories of using the brand 'CoE' within the healthcare, research, education, information technology 
and industry. There were some key milestones commonly applicable to many CoEs; however, there was inconsistent use and self-designation of the brand ' $\mathrm{CoE}$ ' without approval by an independent, external process of evaluation, and with high ambiguity between 'CoE' and the ordinary 'institution' or 'centre'. In the developing world, the concept of CoE is getting significant attention, particularly in research and higher education sectors where senior professors are fairly concentrated as our analysis pinpoints. Our review led us to define CoE as a team of specialised expertise or organisational environment that is established to provide outstanding healthcare, research, education and training, regulatory, information technology or industrial services, and support in high levels of efficient and effective performance.

Our analysis showed that a comprehensive framework is needed to guide and inspire an institution as a CoE. There were some existing frameworks that the CoEs used as a benchmark to shape the establishment and implementation of their CoEs; however, there were some important limitations with the frameworks:

1. The frameworks were limited to demarcating the unique features of a $\mathrm{CoE}$ as compared with an ordinary institution.

2. The frameworks were limited to specific facilities or services without analysis at a larger scale.

3 . The frameworks lacked parameters and levels of indicators to use to follow-up or improve the performance of the CoEs, unlike many accreditation requirements for different research and education ventures.

4. The frameworks were not sufficient to enhance CoEs to acquire excellence in both research and education when these two ventures are allied. There were many CoEs tagged as 'CoE for Research and Education'. As one compliments the other, it could be possible to achieve excellence in both as a singular goal.

5. Giving particular emphasis to CoEs in developing countries, the frameworks did not recognise the issue of resource potential and stewardships in such settings.

The scoping review indicates that highly specialised expertise is one of the layers on top, with the number and multidisciplinary nature of the experts influencing the competency of a $\mathrm{CoE}$ with the rapidly changing knowledge and development landscape. The CoE needs to ensure that it has the right technical, administrative and operational functions in place, bringing in the right subject-matter expertise at the right time to deliver targeted outcomes. The appointment of expertise needs to be merit based, taking into account each member's education, training, experience and the broader vision of long-term requirements.

State-of-the-art infrastructure is preeminent in defining and transforming an institution as a CoE. Such infrastructure raises productivity and inspires specialised expertise from different contexts and countries to visit, practice and collaborate. Structurally, the CoEs could be a standalone promise or a confirmed part of a legal institution as a separate division in an institution, or a hub location for multicountry functions. The CoE needs to promote a global view aimed at enhancing healthy competitions on a global platform and promoting the development of globalised knowledge. It should benchmark its infrastructure and performance against equivalent CoEs in other settings or countries.

The CoE needs to cultivate innovations to create and transform new ideas, knowledge and procedures that incrementally improve its success and stay ahead in the face of extreme competition. The CoE needs to introduce cutting-edge technologies, devices, or applications that maximise its productivity and competitiveness. For a $\mathrm{CoE}$ that focuses on R\&D, its research outputs should have a high impact on the knowledge economy for substantial changes beyond scholarly roles. The CoE needs to work to convert its academic or research outputs into new business ventures through an entrepreneurship platform. For a CoE that focuses on service delivery, it should provide services that consistently delight customers' individual needs and preferences. This includes developing standards of service quality and continuously measuring improvements to raise service quality and create more efficient methods of service delivery. The CoE needs to value accreditation schemes by an external evaluator to continuously measure and assure service quality and enhance its status and reputation.

Leadership is one of the critical components of a CoE. The CoE requires a powerful, goal-oriented leadership to passionately lead the team in a given direction and drives toward success. The CoE leader should have the maximum commitment to achieving excellence, with the potential to influence the overall functions and long-term visions of the CoE. The leadership should explore sustainable financing mechanisms which could be sourced from government institutions, funding agencies, publicprivate partnerships or generation of revenues through consultancy, training or research services. The leadership should make sure that its staff is highly motivated and ambitious. The CoE needs to develop and implement an organisational structure that works best for its particular interest. This should be supported by a roadmap and strategy that defines the broader vision, mission, goals and objective that deal with the long-term desired status of the CoE.

\section{CONCLUSION}

CoEs have significant scientific, political, economic and social impacts. However, there are inconsistent use and self-designation of the brand without approval by an independent, external process of evaluation, and with high ambiguity between 'CoEs' and the ordinary 'institutions' or 'centres'. A comprehensive framework is needed to guide and inspire an institution as a $\mathrm{CoE}$ and to help government and funding institutions shape and oversee CoEs.

Twitter Abebaw Fekadu @abebawfekadu 
Acknowledgements The World Bank financially supports the Centre for Innovative Drug Development and Therapeutic Trials for Africa (CDT-Africa).

Contributors Conceptualisation, methodology, first draft and the guarantor: TM and AF. Revised the draft: YW, CO, AH, AB, MG, GM, GY, AC and EM. All authors have read, reviewed and approved the final manuscript for publication.

Funding The authors have not declared a specific grant for this research from any funding agency in the public, commercial or not-for-profit sectors.

Competing interests None declared.

Patient consent for publication Not applicable.

Ethics approval This study does not involve human participants.

Provenance and peer review Not commissioned; externally peer reviewed.

Data availability statement All data relevant to the study are included in the article or uploaded as online supplemental information.

Supplemental material This content has been supplied by the author(s). It has not been vetted by BMJ Publishing Group Limited (BMJ) and may not have been peer-reviewed. Any opinions or recommendations discussed are solely those of the author(s) and are not endorsed by BMJ. BMJ disclaims all liability and responsibility arising from any reliance placed on the content. Where the content includes any translated material, BMJ does not warrant the accuracy and reliability of the translations (including but not limited to local regulations, clinical guidelines, terminology, drug names and drug dosages), and is not responsible for any error and/or omissions arising from translation and adaptation or otherwise.

Open access This is an open access article distributed in accordance with the Creative Commons Attribution Non Commercial (CC BY-NC 4.0) license, which permits others to distribute, remix, adapt, build upon this work non-commercially, and license their derivative works on different terms, provided the original work is properly cited, appropriate credit is given, any changes made indicated, and the use is non-commercial. See: http://creativecommons.org/licenses/by-nc/4.0/.

\section{ORCID iDs}

Tsegahun Manyazewal http://orcid.org/0000-0002-8360-7574

Abebaw Fekadu http://orcid.org/0000-0003-2219-0952

\section{REFERENCES}

1 Fekadu A, Oppenheim C, Manyazewal T, et al. Understanding the key processes of excellence as a prerequisite to establishing academic centres of excellence in Africa. BMC Med Educ 2021;21:36.

2 Elrod JK, Fortenberry JL. Centers of excellence in healthcare institutions: what they are and how to assemble them. BMC Health Serv Res 2017:17:425

3 Nakov R, Sarafov S, Gospodinova M, et al. Transthyretin amyloidosis: testing strategies and model for center of excellence support. Clin Chim Acta 2020;509:228-34.

4 Itri JN, Bakow E, Woods J. Creating an outpatient center of excellence in CT. J Am Coll Radiol 2014;11:1137-43.

5 Reichert J, Furlong G. Five key pillars of an analytics center of excellence, which are required to manage populations and transform organizations into the next era of health care. Nurs $A d m Q$ 2014;38:159-65.

6 Blokdyk G. Center of excellence a complete guide. 2019 Ed. Australia: Emereo Pty Limited, 2019.

7 Santos-Moreno P, Caballero-Uribe CV, Massardo ML, et al. Systematic and progressive implementation of the centers of excellence for rheumatoid arthritis: a methodological proposal. Clin Rheumatol 2017;36:2855-8.

8 Walshe R, Herrmann-Frank A, Diehl V. [Center of excellence, cancer center, competence network: confusion of terminology?]. Dtsch Med Wochenschr 2002;127:913-4.

9 Masri A, Bukhari S, Eisele YS, et al. Molecular imaging of cardiac amyloidosis. J Nucl Med 2020;61:965-70.

10 Drake J, Schreiber KC, Lopez R, et al. Establishing a center of excellence for hereditary diffuse gastric cancer syndrome. J Surg Oncol 2019;119:673-4.

11 El-Eshmawi A, Castillo JG, Tang GHL, et al. Developing a mitral valve center of excellence. Curr Opin Cardiol 2018;33:155-61.

12 Nwafor IA, Chinawa JM, Adiele DK, et al. Management of complex $\mathrm{CHD}$ at the National cardiothoracic center of excellence, University of Nigeria teaching Hospital, Enugu: the role of foreign cardiac missions in 3.5 years. Cardiol Young 2017;27:1174-9.

13 De Angelis F, Abdelgawad M, Rizzello M, et al. Perioperative hemorrhagic complications after laparoscopic sleeve gastrectomy: four-year experience of a bariatric center of excellence. Surg Endosc 2017:31:3547-51.

14 Sejdić E, Rothfuss MA, Stachel JR, et al. Innovation and translation efforts in wireless medical connectivity, telemedicine and eMedicine: a story from the RFID center of excellence at the University of Pittsburgh. Ann Biomed Eng 2013;41:1913-25.

15 Fife RS. Development of a comprehensive women's health program in an academic medical center: experiences of the Indiana university national center of excellence in women's health. $J$ Womens Health 2003:12:869-78.

16 JDRF News Column. New stem cell centre of excellence opens in Cambridge. Pract Diab Int 2004:21:276.

17 Singh M, Sawarkar D, Sharma BS. Neurosurgery at all India Institute of medical sciences, a center of excellence: a success story. Neurol India 2015;63:589-96.

18 Santos-Moreno P, Alvis-Zakzuk NJ, Villarreal-Peralta L, et al. A comprehensive care program achieves high remission rates in rheumatoid arthritis in a middle-income setting. experience of a center of excellence in Colombia. Rheumatol Int 2018;38:499-505.

19 Manyazewal T, Woldeamanuel Y, Blumberg HM, et al. The potential use of digital health technologies in the African context: a systematic review of evidence from Ethiopia. NPJ Digit Med 2021;4:125.

20 The African research universities alliance (ARUA) centers of excellence. Accra, Ghana. Available: https://arua.org.za/centres-ofexcellence/

21 Arksey H, O'Malley L. Scoping studies: towards a methodological framework. Int J Soc Res Methodol 2005;8:19-32.

22 Levac D, Colquhoun H, O'Brien KK. Scoping studies: advancing the methodology. Implement Sci 2010;5:69.

23 Tricco AC, Lillie E, Zarin W, et al. PRISMA extension for scoping reviews (PRISMA-ScR): checklist and explanation. Ann Intern Med 2018;169:467-73.

24 The University of Texas health science center at Houston (UTHealth). COVID-19 center of excellence. Texas, USA: UTHealth, 2020. https:// www.uth.edu/covid-19/

25 Bialous SA, Nohavova I, Kralikova E, et al. Building capacity in tobacco control by establishing the eastern Europe nurses' center of excellence for tobacco control. Tob Prev Cessat 2020;6:1-12.

26 Lipsitz O, McIntyre RS, Rodrigues NB, et al. Does body mass index predict response to intravenous ketamine treatment in adults with major depressive and bipolar disorder? results from the Canadian rapid treatment center of excellence. CNS Spectr 2020:1-9.

27 Komninaka V, Flevari P, Marinakis T, et al. Outcomes of pregnancies in patients with Gaucher disease: the experience of a center of excellence on rare metabolic Disease-Gaucher disease, in Greece. Eur J Obstet Gynecol Reprod Biol 2020;254:181-7.

28 Araujo-Castro M, Pascual-Corrales E, Martínez San Millan JS, et al. Postoperative management of patients with pituitary tumors submitted to pituitary surgery. experience of a Spanish pituitary tumor center of excellence. Endocrine 2020;69:5-17.

29 Balkhy HH, Amabile A, Torregrossa G. A shifting paradigm in robotic heart surgery: from Single-Procedure approach to establishing a robotic heart center of excellence. Innovations 2020;15:187-94.

30 Tinc PJ, Wolf-Gould C, Wolf-Gould C, et al. Longitudinal use of the consolidated framework for implementation research to evaluate the creation of a rural center of excellence in transgender health. Int $J$ Environ Res Public Health 2020;17:9047.

31 Sarkar T, Karmakar N, Dasgupta A, et al. Quality of life of people living with HIV/AIDS attending antiretroviral clinic in the center of excellence in HIV care in India. J Educ Health Promot 2019;8:226.

32 Neal C, Rusangwa C, Borg R, et al. Cost of treating pediatric cancer at the Butaro cancer center of excellence in Rwanda. J Glob Oncol $2018 ; 4: 1-7$

33 Choque-Velasquez J, Colasanti R, Baffigo-Torre V, et al. Developing the first highly specialized neurosurgical center of excellence in Trujillo, Peru: work in Progress-Results of the first four months. World Neurosurg 2017;102:334-9.

34 Chick JFB, Reddy SN, Pyeritz RE, et al. A survey of pulmonary arteriovenous malformation screening, management, and followup in hereditary hemorrhagic telangiectasia centers of excellence. Cardiovasc Intervent Radiol 2017;40:1003-9.

35 Casanueva FF, Barkan AL, Buchfelder M, et al. Criteria for the definition of pituitary tumor centers of excellence (PTCOE): a pituitary Society statement. Pituitary 2017;20:489-98.

36 Cohen MS. Enhancing surgical innovation through a specialized medical school pathway of excellence in innovation and entrepreneurship: lessons learned and opportunities for the future. Surgery 2017:162:989-93.

37 Doumouras AG, Saleh F, Anvari S, et al. A longitudinal analysis of short-term costs and outcomes in a regionalized center of excellence bariatric care system. Obes Surg 2017;27:2811-7. 
38 Rani PK, Balakrishnanan D, Padhi TR, et al. Role of retinopathy of prematurity (ROP) tertiary centers of excellence in Capacity-building. Indian Pediatr 2016;53 Suppl 2:S85-8.

39 Keto JL, Kemmeter PR. Effect of center of excellence requirement by centers for Medicare and Medicaid services on practice trends. Surg Obes Relat Dis 2008;4:437-40.

40 Nwaka S, Ochem A, Besson D, et al. Analysis of pan-African centres of excellence in health innovation highlights opportunities and challenges for local innovation and financing in the continent. BMC Int Health Hum Rights 2012;12:11.

41 Heining $C$, von Kalle C. What functions do oncological centers of excellence have in future research? ONKOLOGE 2016;22:152-7.

42 Voznesenskaya A, Bougrov V, Kozlov S. Itmo Photonics: center of excellence. InOptics education and outreach IV. International Society for Optics and Photonics 2016;9946:99460V.

43 Bienenstock A, Schwaag Serger S, Benner M. Combining excellence in education, research and impact: inspiration from Stanford and Berkeley and implications for Swedish universities. SNS Forlag 2014.

44 Sobhieh MH, Karimi R, Razmi J. Develop center of excellence (COE) at power plant projects in southern Iran with conceptual model approach to supply chain management in construction industry projects. Journal of Engineering and Applied Sciences 2016;11:967-75.

45 Neely JR, de Supinski BR. Application modernization at LLNL and the Sierra center of excellence. Comput Sci Eng 2017;19:9-18.

46 Hellström T. Centres of excellence as a tool for capacity building. Case study: Canada. Organization for Economic Cooperation and Development: IMHE Higher Education Programme, 2013.

47 Heyes A. An assessment of the nuclear security centers of excellence. Stanley Foundation, 2012.

48 Perdomo HA. Cancer centers of excellence in Colombia: a fundamental way to work together. Urología colombiana 2017;26:157-8

49 Mettrick J, Harburger DS, Kanary PJ. Building Cross-System implementation centers: a roadmap for state and local child serving agencies in developing centers of excellence (COE. Baltimore, MD: The Institute for Innovation \& Implementation, University of Maryland, 2015.

50 Hershko A, Edri MM, Wirtheim E. Harefuah 2015;154:478-542.

51 Cullen L, Greiner J, Greiner J, et al. Excellence in evidence-based practice: organizational and unit exemplars. Crit Care Nurs Clin North Am 2005; 17:127-x

52 Lin C-C, Yang C-H, Cheng A-L, et al. National center of excellence for clinical trials and research at national Taiwan university hospital. Drug Inf J 2009;43:361-3.

53 Craig W, Fisher M, Garcia S. Generalized criteria and evaluation method for center of excellence: a preliminary report. CARNEGIEMELLON UNIV PITTSBURGH PA SOFTWARE ENGINEERING INST, 2009.

54 Patel J, Andrews L. Seven key steps to establishing a center of EXCELLENCE-If you're struggling to optimize your return on investment from enterprise content management and other strategies, this just might offer a solution. Infonomics 2010;40.

55 Marciniak R. Center of excellence as a next step for shared service center. Journal of International Scientific Publication: Economy \& Business. ISBN: ISSN. 2012:1313-2555.

56 Antonowicz D, Kohoutek J, Pinheiro R, et al. The roads of 'excellence' in Central and Eastern Europe. European Educational Research Journal 2017;16:547-67.

57 Gao JJ, Pazdur R. Fda oncology center of excellence during COVID19-Working for patients with cancer. JAMA Oncol 2020. doi:10.1001/ jamaoncol.2020.6783. [Epub ahead of print: 23 Dec 2020].

58 Miranda JJ, Bernabé-Ortiz A, Diez-Canseco F, et al. Towards sustainable partnerships in global health: the case of the CRONICAS centre of excellence in chronic diseases in Peru. Global Health 2016;12:29.

59 Kouchoukos NT. What is a Cardiothoracic Surgical "Center of Excellence"? Ann Thorac Surg 2016;102:1426-7.

60 Melissas J, Stavroulakis K, Tzikoulis V, et al. Sleeve gastrectomy vs Roux-en-Y gastric bypass. data from IFSO-European chapter center of excellence program. Obes Surg 2017;27:847-55.

61 Rábago CA, Clouser M, Dearth CL, et al. The extremity trauma and amputation center of excellence: overview of the research and surveillance division. Mil Med 2016;181:3-12.

62 Mehrotra A, Dimick JB. Ensuring excellence in centers of excellence programs. Ann Surg 2015;261:237-9.

63 Katz IT, Bogart LM, Cloete C, et al. Understanding HIV-infected patients' experiences with PEPFAR-associated transitions at a centre of excellence in KwaZulu natal, South Africa: a qualitative study. AIDS Care 2015;27:1298-303.
64 Itri JN, Bakow E, Woods J. Creating an outpatient center of excellence in CT. J Am Coll Radiol 2014:11:1137-43.

65 Zar HJ. Partnering with centers of excellence in high- and lowmiddle-income countries: a strategy to strengthen child health globally. Pediatr Radiol 2014;44:709-10.

66 Ferguson GM, Froehlich JA. Establishing a center of excellence: the total joint center at the MIRIAM Hospital. R I Med J 2013;96:16-18.

67 Mehrotra A, Sloss EM, Hussey PS, et al. Evaluation of a center of excellence program for spine surgery. Med Care 2013;51:748-57.

68 National Institutes of Health. NIH centers of excellence: Biennial Report of the Director, National Institutes of Health, Fiscal Years 2008 \& 2009. publication no. 11-7701. volume 4. USA: NIH, 2009. https:// report.nih.gov/biennialreport/

69 Sharkey K, Meeks-Sjostrom D, Baird M. Challenges in sustaining excellence over time. Nurs Adm Q 2009;33:142-7.

70 Anderson RT, Weisman CS, Scholle SH, et al. Evaluation of the quality of care in the clinical care centers of the National centers of excellence in women's health. Womens Health Issues 2002;12:309-26.

71 Pennsylvania department of human services (DHS). Centers of excellence: thinking about addiction a different way. Pennsylvania, USA: Pennsylvania DHS, 2016.

72 Househ M, Al-Tuwaijri M, Al-Dosari B. Establishing an electronic health center of research excellence (E-CoRE) within the Kingdom of Saudi Arabia. Journal of Health Informatics in Developing Countries 2010;4

73 Rocco G, Affonso D, Mayberry L, et al. Center of excellence to build nursing scholarship and improve health care in Italy. Journal of Nursing Scholarship 2015;47:170-7.

74 Kumar S, Abowd G, Abraham WT, et al. Center of excellence for mobile sensor Data-to-Knowledge (MD2K). IEEE Pervasive Comput 2017; 16:18-22.

75 Dieye B, Affara M, Sangare L, et al. West Africa international centers of excellence for malaria research: drug resistance patterns to Artemether-Lumefantrine in Senegal, Mali, and the Gambia. Am J Trop Med Hyg 2016;95:1054-60.

76 Fekadu A, Hailu A, Makonnen E, et al. Short-Term impact of celebrating the International clinical trial day: experience from Ethiopia. Trials 2017;18:332

77 McCarthy J. ESRF: a quest for excellence in service to users. Synchrotron Radiat News 2017;30:31-6.

78 Bloch C, Schneider JW, Sinkjær T. Size, accumulation and performance for research grants: examining the role of size for centres of excellence. PLoS One 2016;11:e0147726.

79 Borlaug SB. Moral hazard and adverse selection in research funding: centres of excellence in Norway and Sweden. Science and Public Policy 2016;43:352-62.

80 Pislyakov V, Shukshina E. Measuring excellence in Russia: highly cited papers, leading institutions, patterns of national and international collaboration. Journal of the Association for Information Science and Technology 2014;65:2321-30.

81 Harris TB, Salihu HM. 2019 health equity summer research Summit organized by the center of excellence in health equity, training and research, Baylor College of medicine, Houston, Texas 77030, USA on June 18th, 2019. Int J MCH AIDS 2020;9:S1-47.

82 The World Bank. Eastern and southern Africa higher education centers of excellence. Washington, D.C., USA: World Bank, 2021. https://projects.worldbank.org/en/projects-operations/project-detail/ P151847

83 Giacomini KM, Lin L, Altman RB. Research projects supported by the University of California, San Francisco-Stanford center of excellence in regulatory science and innovation. Clin Pharmacol Ther 2019;105:815-8.

84 Terama E, Smallman M, Lock SJ, et al. Beyond Academia Interrogating Research Impact in the Research Excellence Framework. PLoS One 2016;11:e0168533.

85 Cofrancesco J, Barone MA, Serwint JR, et al. Development and implementation of a School-Wide Institute for excellence in education to enable educational scholarship by medical school faculty. Teach Learn Med 2018;30:103-11.

86 Rugen KW, Watts SA, Janson SL, et al. Veteran Affairs centers of excellence in primary care education: transforming nurse practitioner education. Nurs Outlook 2014;62:78-88.

87 Bittner NP, Ericson K, McCarthy M, et al. Focus on excellence: making a difference through global initiatives. Nurs Educ Perspect 2013;34:25-8.

88 Balaji R, Venkadasalam S. Developing a marine engineering centre of excellence for competency-based training. WMU Journal of Maritime Affairs 2017:16:293-311.

89 Scheuermann JS, Reddin JS, Opanowski A, et al. Qualification of national cancer Institute-Designated cancer centers for quantitative PET/CT imaging in clinical trials. J Nucl Med 2017;58:1065-71. 
90 Grant LA, Gulsvig J, Call J. Measuring excellence: the new quality agenda. Provider 2006;32:1-7.

91 Wang M. Cas center for excellence in quantum information and quantum physics: exploring frontiers of quantum physics and quantum technology. Natl Sci Rev 2017;4:144-52.

92 Geiger J. Establishing a center of excellence. Information Management 2006;16:24.

93 Nqampoyi V, Seymour LF, Laar DS. Effective business process management centres of excellence. InInternational Conference on Research and Practical Issues of Enterprise Information Systems, Springer, Cham, 2016:207-22.

94 Brusoni M, Damian R, Sauri JG, et al. The concept of excellence in higher education. Retrieved on March 2014;18:2016.
95 Fetrow J, Royster E, Morin D, et al. Development and Implementation of a National Center of Excellence in Dairy Production Medicine Education for Veterinary Students: Description of the Effort and Lessons Learned. J Vet Med Educ 2020;47:250-62.

96 NYC Health + Hospitals. Mayor de Blasio and Taskforce on racial inclusion and equity announce new COVID-19 centers of excellence. New York, USA: NYC Health + Hospitals, 2020. https://www.nychealt handhospitals.org/pressrelease/mayor-announces-three-new-covid19-centers-of-excellence-gotham-health-sites/

97 Addis Ababa Science and Technology University (AASTU). The Artificial Intelligence \& Robotics Center of Excellence. Addis Ababa, Ethiopia: AASTU, 2021. http://www.aastu.edu.et/research-andtechnology-transfer-vpresident/the-artificial-intelligence-roboticscenter-of-excellence/ 